\title{
The glutamine synthetase gene family in Populus
}

\author{
Vanessa Castro-Rodríguez ${ }^{1}$, Angel García-Gutiérrez ${ }^{1}$, Javier Canales ${ }^{1}$, Concepción Avila ${ }^{1}$, Edward G Kirby ${ }^{2}$ and
} Francisco M Cánovas ${ }^{1 *}$

\begin{abstract}
Background: Glutamine synthetase (GS; EC: 6.3.1.2, L-glutamate: ammonia ligase ADP-forming) is a key enzyme in ammonium assimilation and metabolism of higher plants. The current work was undertaken to develop a more comprehensive understanding of molecular and biochemical features of GS gene family in poplar, and to characterize the developmental regulation of GS expression in various tissues and at various times during the poplar perennial growth.

Results: The GS gene family consists of 8 different genes exhibiting all structural and regulatory elements consistent with their roles as functional genes. Our results indicate that the family members are organized in 4 groups of duplicated genes, 3 of which code for cytosolic GS isoforms (GS1) and 1 which codes for the choroplastic GS isoform (GS2). Our analysis shows that Populus trichocarpa is the first plant species in which it was observed the complete GS family duplicated. Detailed expression analyses have revealed specific spatial and seasonal patterns of GS expression in poplar. These data provide insights into the metabolic function of GS isoforms in poplar and pave the way for future functional studies.

Conclusions: Our data suggest that GS duplicates could have been retained in order to increase the amount of enzyme in a particular cell type. This possibility could contribute to the homeostasis of nitrogen metabolism in functions associated to changes in glutamine-derived metabolic products. The presence of duplicated GS genes in poplar could also contribute to diversification of the enzymatic properties for a particular GS isoform through the assembly of GS polypeptides into homo oligomeric and/or hetero oligomeric holoenzymes in specific cell types.
\end{abstract}

\section{Background}

Glutamine synthetase (GS; EC 6.3.1.2, L-glutamate: ammonia ligase ADP-forming) catalyzes the ATP-dependent addition of ammonium $\left(\mathrm{NH}_{4}^{+}\right)$to the $\gamma$-carboxyl group of glutamate to produce glutamine and acts as the center for nitrogen flow in plants. Glutamate synthase (Fd-GOGAT, EC 1.4.7.1; NADH-GOGAT, EC 1.4.1.1) then catalyzes the conversion of glutamine and 2-oxoglutarate to produce two molecules of glutamate, one of which participates in further ammonium assimilation via GS while the other donates reduced nitrogen for all nitrogen-containing biomolecules [1]. The ammonium assimilated by GS in the production of glutamine can come from various sources, including direct uptake from the soil, reduction of nitrate and nitrite, photorespiration, deamination of phenylalanine catalyzed by

\footnotetext{
* Correspondence: canovas@uma.es

'Departamento de Biología Molecular y Bioquímica, Instituto Andaluz de Biotecnología, Universidad de Málaga, 29071-Málaga, Spain

Full list of author information is available at the end of the article
}

phenylalanine ammonia-lyase, and the catabolic release of ammonium during the mobilization of vegetative storage proteins and during senescence.

Multiple nuclear encoded GS polypeptides are expressed in photosynthetic and non-photosynthetic tissues of higher plants and these polypeptides are assembled into oligomeric isoenzymes located either in the cytosol or in the chloroplast [2,3]. Recently it has been reported that plant GS holoenzyme has a decameric structure composed of two face-to face pentameric rings of subunits, with active sites formed between every two neighboring subunits within each ring $[4,5]$. Phylogenetic studies of nucleotide and amino acid sequences have shown that genes for chloroplastic and cytosolic GS in plants form two sister groups with a common ancestor which diverged by duplication before the split between angiosperms and gymnosperms [6].

In angiosperms there are two main isoforms of GS, cytosolic GS (GS1) and a chloroplastic GS (GS2). This suggests that there are several distinct pathways for
C Biomed Central

() 2011 Castro-Rodríguez et al; licensee BioMed Central Ltd. This is an Open Access article distributed under the terms of the Creative Commons Attribution License (http://creativecommons.org/licenses/by/2.0), which permits unrestricted use, distribution, and reproduction in any medium, provided the original work is properly cited. 
glutamine production, both spatially and temporally. In developing leaves, glutamine is mainly produced in chloroplasts through the activity of the GS2 isoenzyme. The ammonium assimilated into glutamine in young leaves is produced by nitrate reduction and through photorespiration $[7,8]$. Alternatively, cytosolic GS1 primarily generates glutamine for intercellular nitrogen transport. The cytosolic enzyme assimilates ammonium taken up from the soil and released in the biosynthesis of phenylpropanoids and nitrogen remobilization [9-11]. Thus, GS1 genes are differentially expressed in roots and in vascular tissues. Molecular analysis of genomic GS sequences from a number of angiosperm species has shown that the cytosolic GS1 genes belong to a small multigene family, whereas, the chloroplastic GS2 is encoded by a single gene $[9,10]$.

GS plays a fundamental role in growth and development of woody plants $[11,12]$. In poplar, this critical role for GS has been clearly demonstrated through studies of transgenic poplars that express ectopically the pine cytosolic GS. Transgenic poplars exhibit enhanced vegetative growth $[13,14]$, enhanced resistance to drought stress at both ecophysiological and enzymatic and non-enzymatic antioxidant levels [15], and enhanced nitrogen use efficiency [16]. These results clearly lead to the conclusion that in poplar GS activity is a limiting factor in growth and development. The current work was undertaken to develop a more comprehensive understanding of molecular and biochemical features of GS gene family in poplar, to establish an understanding of the roles of specific members of the poplar GS gene family during development, and to characterize the developmental regulation of $G S$ expression in various tissues and at various times during the poplar perennial growth.

\section{Results}

Identification and structural analysis of poplar GS genes A search of the Populus trichocarpa whole genomic sequence at the JGI [17] allowed us to identify regions containing GS sequences. Eight sequences containing a complete ORF as well as the structural and regulatory elements for a functional gene were retained for further study. The poplar genome data base also contains 9 GS pseudogenes as well as an additional GS gene showing a high identity level to the GS genes in archaebacteria. The full-length cDNAs (FLcDNAs) of the 8 GS genes were analyzed and the characteristics of the polypeptides encoded by their ORFs were compared (Table 1). The results of all these bioinformatic analyses allowed the identification of 6 genes coding for a cytosolic GS iosenzyme (GS1) and 2 genes coding for a plastidic GS isoenzyme (GS2). Additionally, our analysis suggests that the GS gene family in poplar is organized in 4 groups of duplicated genes, PtGS1.1, PtGS1.2, PtGS1.3 and PtGS2. According to the original identification numbers at the JGI database, poplar GS1 genes were named PtGS1.1-710678 and PtGS1.1-831163, PtGS1.2-716066 and PtGS1.2-819912, PtGS1.3-827781 and PtGS1.3-834185. Following the same criteria, poplar GS2 genes were named PtGS2-725763 and PtGS2-820914. The genetic distance between the different GS genes was calculated considering the complete genomic sequence of the individual members of the gene family confirming the existence of the GS gene duplicates.

The four duplicated GS genes were positioned in the linkage groups (LG) or scaffolds present in the Populus trichocarpa genome (Figure 1). The genomic regions where the GS genes were located were examined in detail by determination of the open reading frames (ORFs) upstream and downstream of the specific GS genes and cross-alignment of these adjacent regions between the gene pairs. Several duplicated genes were collinearly positioned for the PtGS1.1, PtGS1.2 and PtGS2 duplicates. However, it was not possible to localize the PtGS1.3 duplicate because the region dowstream PtGS1.3-827781 was not present in the scaffold where the gene is located (Figure 1). Non-duplicated genes were also observed near the GS genes, as well as internal duplications located on the same chromosome.

Table 1 List of GS gene sequences containing a complete open reading frame (ORF) in the genome of Populus trichocarpa

\begin{tabular}{|c|c|c|c|c|c|c|}
\hline Gene & $\begin{array}{c}\text { FL cDNA } \\
\text { (bp) }\end{array}$ & $\begin{array}{c}\text { ORF } \\
\text { (amino acids) }\end{array}$ & MW (kDa) & $\mathrm{pl}$ & Name & Isoenzyme \\
\hline estExt_Genewise1_v1.C_LG_X4165 & 1299 & 432 & U: 47894.2 P: 42291.5 & U: 6.48 P: 5.34 & PtGS2-725763 & PtGS2 \\
\hline estExt_fgenesh4_pg.C_LG_VIIII790 & 1299 & 432 & U: 47746.9 P: 42172.2 & U: 6.48 P: 5.33 & PtGS2-820914 & \\
\hline estExt_fgenesh4_pm.C_LG_IV0266 & 1074 & 357 & 39355.4 & 5.52 & PtGS1.1-831163 & PtGS1.1 \\
\hline estExt_Genewise1_v1.C_LG_II2125 & 1077 & 358 & 39448.5 & 5.95 & PtGS1.1-710678 & \\
\hline estExt_fgenesh4_pg.C_LG_VII0739 & 1071 & 356 & 38973.0 & 5.53 & PtGS1.2-819912 & PtGS1.2 \\
\hline estExt_Genewise1_v1.C_LG_V3325 & 1071 & 356 & 39057.0 & 5.14 & PtGS1.2-716066 & \\
\hline estExt_fgenesh4_pm.C_LG_XII0003 & 1071 & 356 & 39092.0 & 5.86 & PtGS1.3-834185 & PtGS1.3 \\
\hline estExt_fgenesh4_pg.C_1220090 & 1071 & 356 & 39207.2 & 5.81 & PtGS1.3-827781 & \\
\hline
\end{tabular}




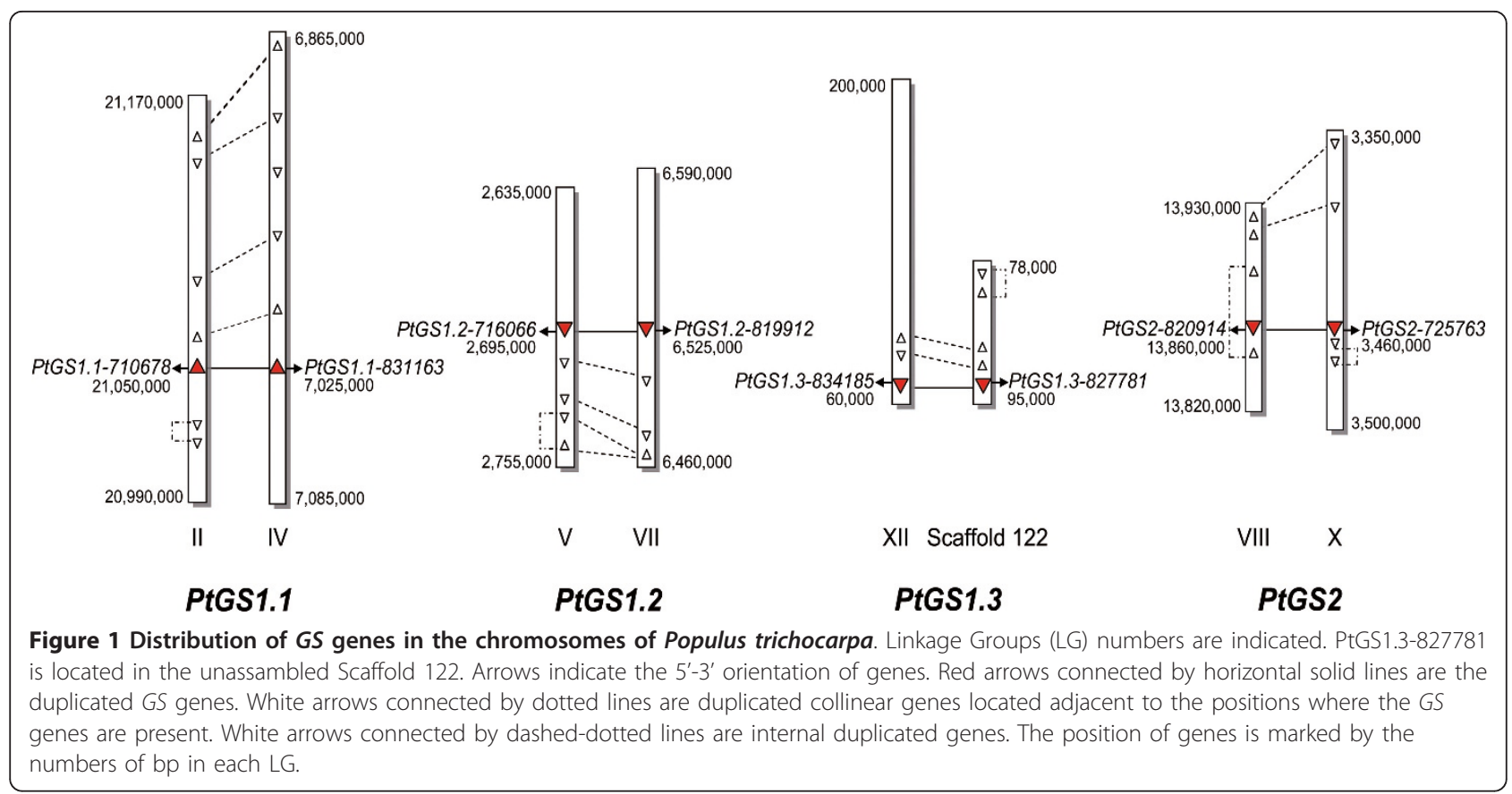

Structural analysis of the GS gene family in poplar was performed by comparison of the exon/intron organization. As shown in Figure 2 the size of the exons is generally well conserved in the four duplicates, PtGS1.1, PtGS1.2, PtGS1.3 and PtGS2. However, the genomic structure is substantially different at the intron regions with introns significantly divergent in size and sequence. In contrast to these observed differences among the gene duplications, the exon/intron boundaries are almost identical between the two members of each duplicate (Figure 2). The PtGS2 and PtGS1.2 duplicates contain 13 exons and 12 introns, the PtGS1.3 duplicate presents 12 exons and 11 introns, and the PtGS.1.1 duplicate contains 11 exons and 10 introns. Interestingly, exon 6 in the PtGS1.1 duplicate represents the fusion of exons 6 and 7 in the PtGS1.2, PtGS1.3 and

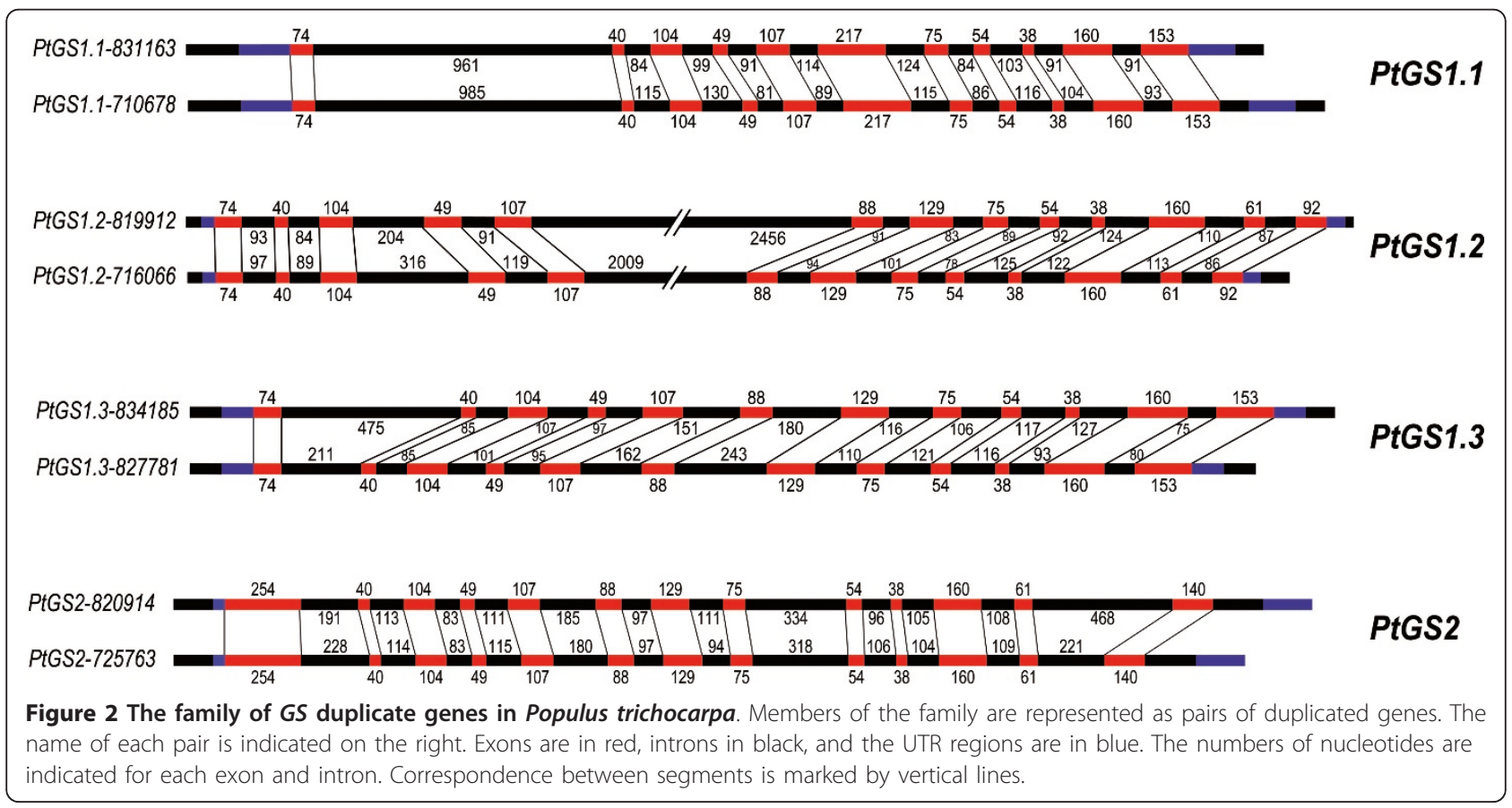


PtGS2 duplicates. On the other hand, the last exon in the PtGS1.1 and PtGS1.3 duplicates represents the fusion of exons 12 and 13 in the PtGS1.2 duplicate. It is interesting to note the presence of an intron of more than $2 \mathrm{~kb}$ interrupting exons 5 and 6 in the PtGS1.2 duplicate.

\section{Comparative analysis of GS gene families in sequenced plant genomes}

To examine the evolutionary relationships of poplar GS genes we performed a cladistic analysis based on deduced amino acid sequences, including the complete GS gene families from the sequenced genomes of Arabidopsis, rice, grape, sorghum and poplar. Pine and spruce GS genes were also included in this comparative analysis (Figure 3). Phylogenetic reconstruction at the molecular level shows the separation of cytosolic (GS1) and chloroplastic (GS2) sequences in angiosperms as two well differentiated clusters. Figure 3 also shows that poplar duplicates for GS2 and GS1 genes were distributed in the two clusters. GS1 genes from Arabidopsis, rice, grape and sorghum were distributed in three subfamilies and the PtGS1.2 and PtGS1.3 duplicates were clearly associated to two of these subfamilies. In contrast, the PtGS1.1 duplicate was outside the conserved GS1 subfamilies and was more closely aligned with the GS1 isoforms of gymnosperms that group outside the main subfamilies of GS1 in angiosperms. However, these data should be interpreted with caution because the support values of the clades are moderate.

\section{Regulatory regions in the poplar GS genes}

In order to get insight into the function of GS genes in poplar, the presence of regulatory elements in the 5'upstream regions was investigated. According to results previously obtained in the structural and phylogenetic analyses, we decided to consider exclusively regulatory elements that were present in the two members of a GS duplicate (Figure 4). In the PtGS1.1, PtGS1.2 and PtGS1.3 genes, these common regulatory elements were found concentrated in the proximal region of the promoter (about 600 bp upstream the initiation of translation). In contrast, the presence of common regulatory elements spanned a major region in the promoter of the PtGS2 duplicate (about 1300 bp upstream the initiation of translation). Putative regulatory elements involved in the interaction with Myb trancription factors were identified exclusively in the PtGS1.3 duplicate. Light-responsive elements such as GATA boxes were identified in all gene duplicates except PtGS1.2. Regulatory elements involved in tissue-specific gene expression (mesophyll, roots) were identified in all genes except PtGS1.3, whereas ABA response elements were present in the promoters of PtGS1.2 duplicates. Boxes specific to cytokinin response were identified in all GS genes but auxin response elements were exclusively found in PtGS1.1. The poplar GS2 promoter contains a sequence of about 200 bp showing a $90 \%$ identity with light-regulatory elements that have been functionally characterized in the GS2 of pea and common bean [18]. Finally, the presence of AT-rich regions was detected in all GS promoters although they were much less abundant in the PtGS2 duplicate.

\section{Organ-specific expression of duplicate GS genes in poplar} To understand the regulation of the GS gene family in poplar and obtain further insight into the biological roles of members in the gene family, GS expression was precisely quantified spatial and temporally. Total RNA was extracted from different organs and the relative abundance of GS transcripts was determined quantitatively by real-time PCR (qPCR). In all cases the transcript levels were normalized by comparison with expression levels of reference genes (as described in Material and Methods). Two month-old hybrid poplars were divided into above-ground and root-regions (Figure 5). The aerial region included the meristematic apex (A), young leaves and stem internodes (A1), intermediate leaves and stem internodes (A2), mature leaves and stem internodes (A3). Aerial regions A1, A2 and A3 were further subdivided in lamina of the leaf (L), leaf vein $(\mathrm{V})$ and stem $(\mathrm{S})$. The root region included the main root close to the root crown (R1) and the secondary root masses (R2). As shown in Figure 5, gene expression profiles of PtGS1.1, PtGS1.2, PtGS1.3 and PtGS2 differed significantly in the samples examined. PtGS1.1 transcripts were particularly abundant in the aerial regions containing intermediate and mature leaves (A2 and A3) and in R2. Interestingly, maximum levels of PtGS1.1 expression were observed in the leaf lamina (L2, L3) with decreased abundance in the leaf veins (V2, V3). Minor levels of gene expression were observed in petioles (P2, P3) and stems (S2, S3). For the PtGS1.2 duplicate the highest transcript abundance was observed in the secondary root masses (R2), while about a half of this value was observed in petioles (P2, P3) and stems (S2, S3) of the aerial parts (A1 and A2). Much lower levels of PtGS1.2 transcripts were detected in remaining samples. Figure 5 also shows that expression of the PtGS1.3 duplicate was predominant among the poplar GS1 genes, and high levels of PtGS1.3 transcripts were observed in the apex, aerial and root sections. Furthermore, levels of PtGS1.3 transcripts were highest of the poplar GS gene family in the apex. It is important to note that in the aerial sections, expression of PtGS1.3 was clearly associated with samples enriched in vascular tissue, such as petioles (P1, P2 and P3) and stems (S1, S2 and S3) whereas lower levels of gene expression were 


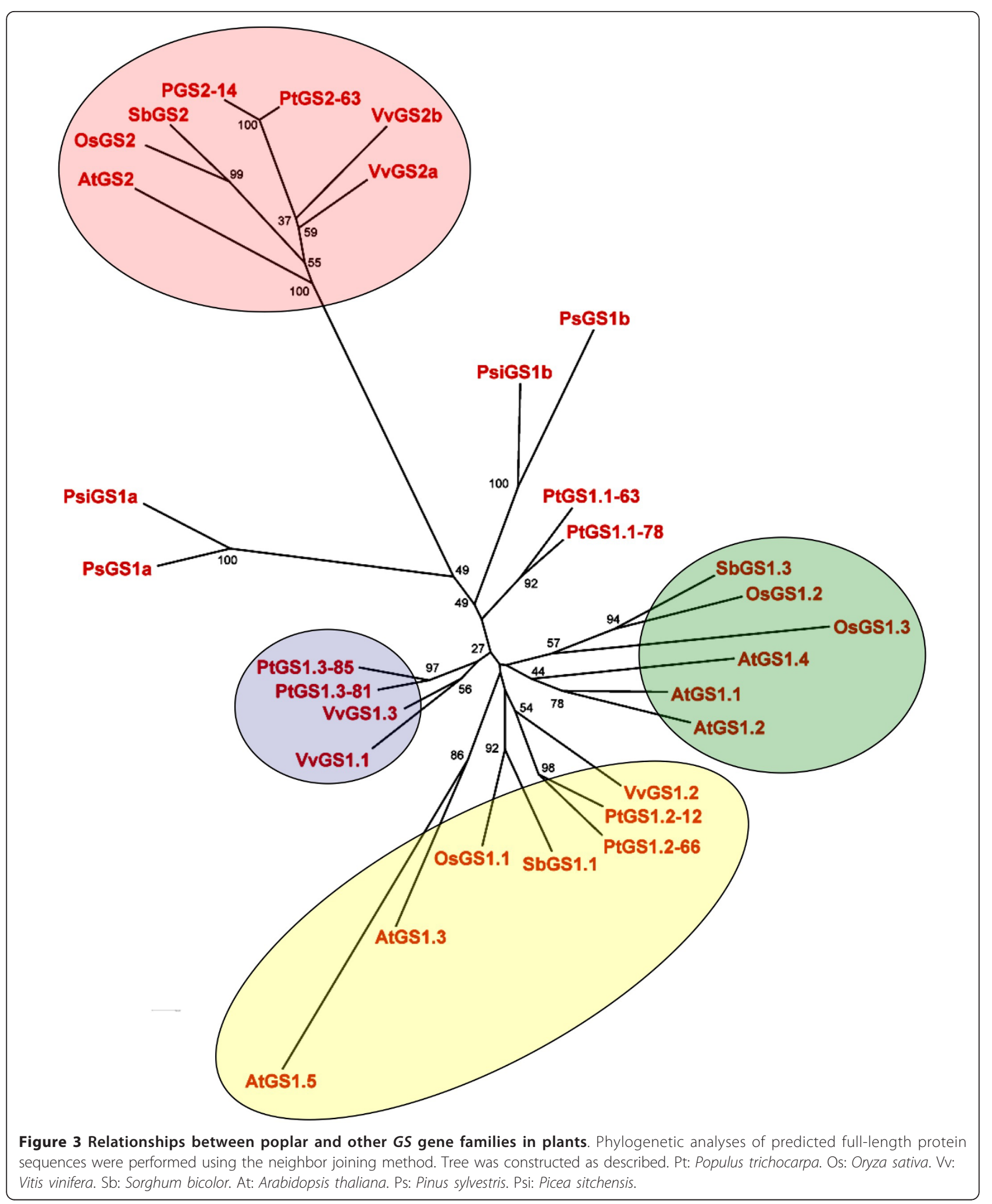




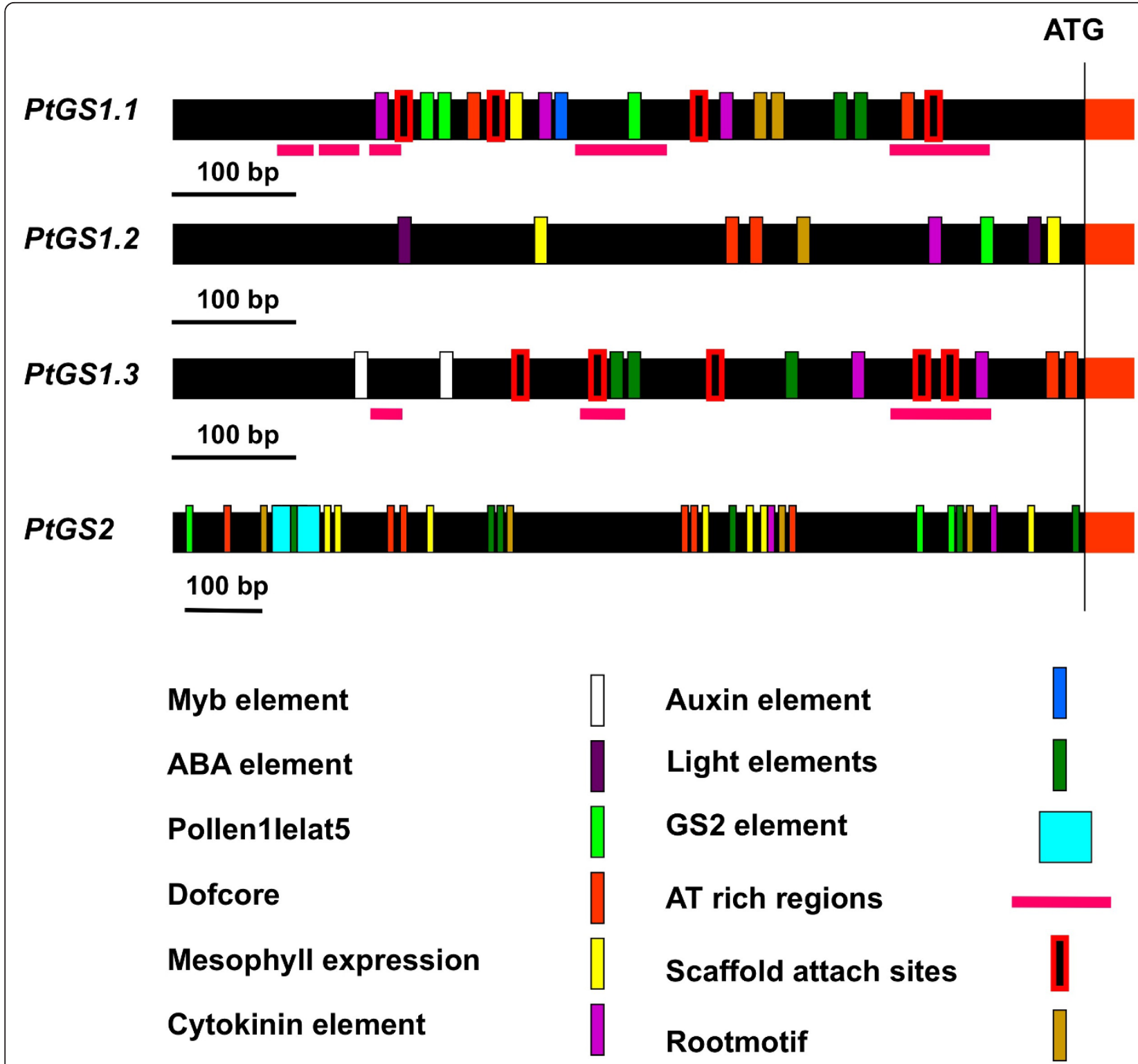

Figure 4 The regulatory regions of the poplar GS genes. The 5' upstream regions of GS genes are represented. Regulatory elements conserved in each pair of duplicated genes are marked in colours. The position of the ATG is marked on the right.

observed in the leaf lamina in all sections examined. Finally, analysis of the PtGS2 duplicate revealed that the transcripts of this family member were the most abundant in the young leaves (A1), and decreased progressively from the top to the bottom of the tree, with the lowest values detected in the roots.

In order to determine if there was a correspondence between the expression patterns of the GS transcripts and the distribution of GS polypeptides, we examined the distribution of GS polypeptides in different organs. Total proteins were extracted from leaves, stems and roots of two month-old poplar trees and GS polypeptides in these organs were identified by western blot analysis using antibodies raised against pine GS [19]. It has been previously reported that these antibodies were able to recognize specifically poplar GS polypeptides [13]. Figure 6A shows the identification of two GS polypeptides, GS2 $(45 \mathrm{kDa})$ and GS1 $(40 \mathrm{kDa})$ in the leaf lamina. The GS1 polypeptide was predominant in stems and roots.

In order to investigate the correspondence of GS trancripts and GS polypeptides in the different organs, total proteins from the same protein samples (leaves, stems and roots) were also separated by two-dimensional gel electrophoresis (2D-PAGE), and the GS polypeptides identified by western blotting (Figure 6B). This 


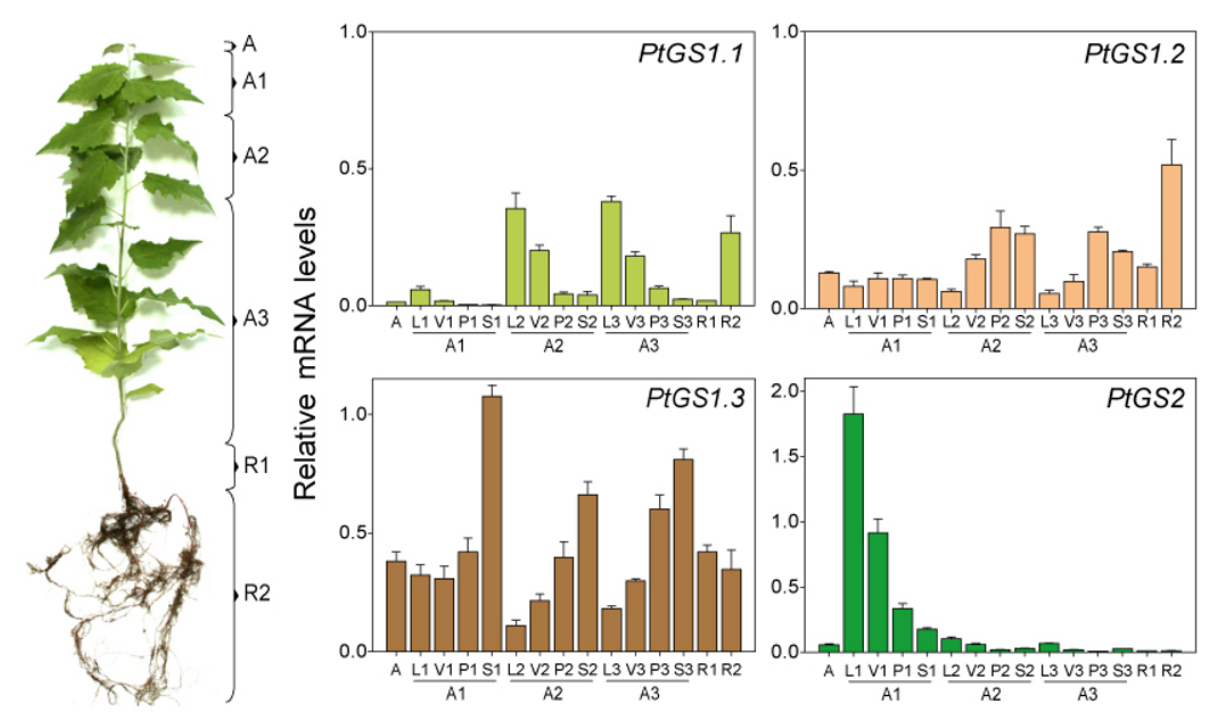

Figure 5 Spatial distribution of GS gene expression in poplar trees. Total RNA was extracted from different organs of 2-month-old hybrid poplar. A, meristematic apex. A1, A2 and A3, aerial sections from the top to the bottom of tree. L, leaf lamina. V, veins. P, petiole. S, stem. R1, primary root. R2, secondary root masses. Transcript levels of PtGS1.1, PtGS1.2, PtGS1.3 and PtGS2 were determined by real-time qPCR analysis as described. Expression levels are presented as relative values to reference genes (actin2 and ubiquitin). The histograms represent the mean values of three independent experiments with standard deviations.

experimental approach allowed us to identify GS polypeptides of different charge among the family of GS polypeptides of the same size. Thus, in the leaf lamina the GS2 polypeptide was resolved as several spots with the most abundant exhibiting a calculated isoelectric point (pI) of 5.26. The GS1 polypeptide was resolved as a major spot of a pI of 5.52. In the stem, two major major spots corresponded to GS1 polypeptides of $\mathrm{pI}$ 5.20 and 5.81. Finally, in the roots the major GS1 spot had a calculated pI of 5.14. These experimental pI values were in the range of the predicted $\mathrm{pI}$ values for poplar GS polypeptides (Table 1).

\section{Seasonal changes in GS gene expression}

We were also interested to know the seasonal changes in the expression of the GS gene family in poplar. Transcript levels of PtGS1.1, PtGS1.2, PtGS1.3 and PtGS2 were quantitatively determined in RNA extracts from leaves, stem, buds and bark of 10-year-old poplar trees (Populus tremula x P. alba, clone INRA 7171 1-B-4). Figure 7 shows that GS duplicates exhibited contrasting patterns of gene expression during annual growth. The expression of the PtGS1.1 duplicate was very low during winter and increased during spring to reach the maximum values at the end of summer and autumn. Interestingly, the peak values of transcripts were observed in leaves. Transcript abundance for the PtGS1.2 duplicate was low in all samples examined at the different seasons of the year. PtGS1.3 was highly expressed in stems buds and bark during all seasons with peak transcript levels during spring and autumn. Interestingly, the levels of PtGS1.3 transcripts were low in leaves except in autumn when levels increased significantly. Finally, high levels of PtGS2 transcripts were exclusively detected in expanding leaves in spring.

\section{Discussion}

The GS gene family in poplar consists of 8 different genes which exhibit all structural and regulatory elements to be potentially considered as functional genes (Table 1). A detailed analysis of the genomic GS sequences suggests that the GS gene family in poplar is organized into 4 groups of duplicated genes, PtGS1.1, PtGS1.2, PtGS1.3 and PtGS2. These GS genes are distributed on separate loci in different chromosomes, and to our knowledge, Populus trichocarpa is the first plant species in which the complete GS family is observed to be duplicated. However, the duplication of a single GS gene has been previously reported in plants. Thus, two copies of GS1 genes have been described in Pisum sativum [20], and more recently the occurrence of two distinct GS2 genes have been reported in Medicago truncatula [21]. Homology-microsynteny analysis of the genomic regions where the GS genes are located strongly suggests that the origin of the duplicated genes is a genome-wide duplication event that occurred approximately $65 \mathrm{Myr}$ and which is still detectable over approximately $92 \%$ of the poplar genome [17]. Following duplication, new copies of a gene may undergo modifications allowing functional diversification, which is a 


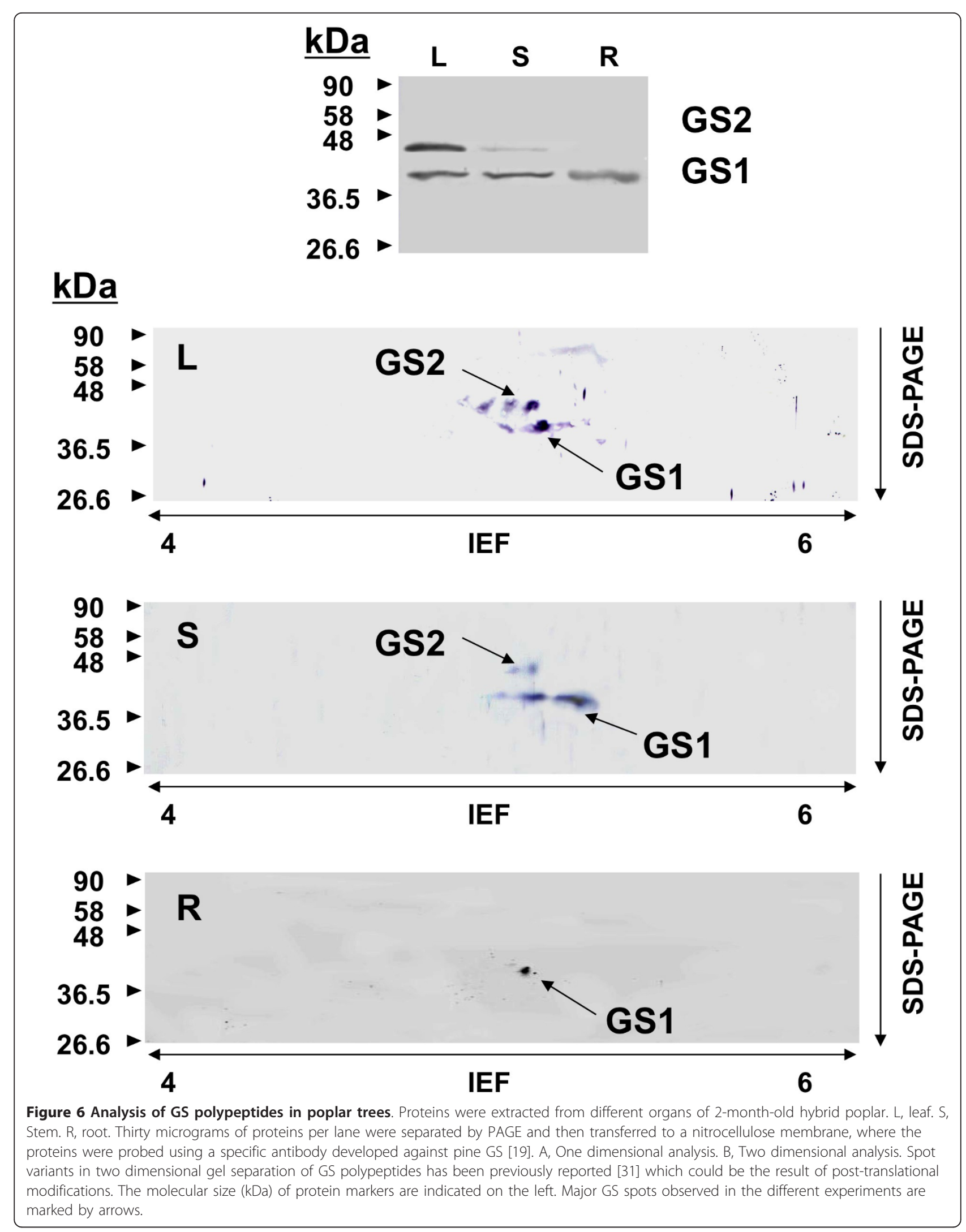




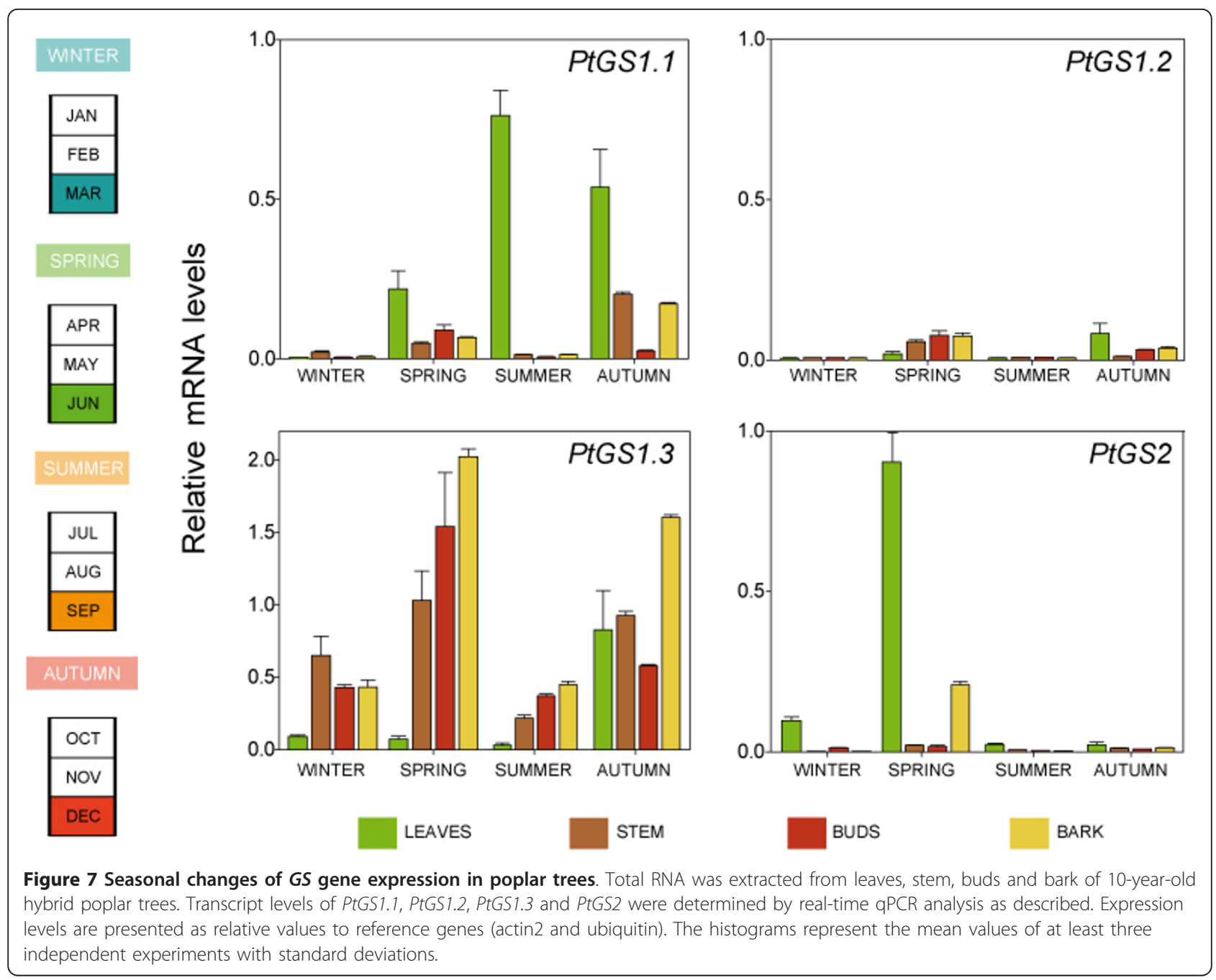

significant source of evolutionary novelty in plants [22]. However, it is also possible that a duplicated gene copy is rapidly lost through pseudogenisation. Interestingly, the exon-intron organization is highly conserved in each pair of duplicated genes in poplar and similar regulatory elements are present in their promoters. These findings provide evidence supporting the expression of GS duplicates in the same cell-types where they are subjected to similar developmental and environmental cues. Furthermore, their coding regions are also quite well-conserved, indicating they encode for essentially the same or very similar GS enzymes. All these results suggest that these duplicated genes could play equivalent roles in poplar nitrogen metabolism.

The molecular and functional analyses of GS gene families in other plants revealed specialization of GS isoenzymes to fulfil specific and non-overlapping roles in nitrogen metabolism depending of the tissue and plant species $[9,10]$. Phylogenetic analyses of poplar GS genes have shown that genes encoding chloroplastic and cytosolic isoforms form two sister groups as previously described for other GS gene families [10]. It has been suggested that the two groups of genes (GS1 and GS2) diverged by duplication from a common ancestor [23] and that this separation occurred before the divergence of gymnosperms/angiosperms [5] but possibly after the appearance of vascular plants [24]. It has been proposed that the gain of a $\mathrm{N}$-terminal transit peptide in GS2 would provide adaptive advantages to plants through enhanced photorespiratory ammonium assimilation in the plastids [12]. Members of the GS1 clade in angiosperms are grouped in subfamilies as previously reported by others [6,10,21]. PtGS1.2 and PtGS1.3 duplicates were found associated to these subfamilies suggesting they could play similar functions to those described for these isoforms. In contrast, the PtGS1.1 duplicate was found separated from PtGS1.2 and PtGS1.3 genes.

The intron-exon organization of the poplar GS genes supports the above hypothesis (Figure 3). The positions and lengths of exons are quite similar for all genes 
suggesting that the structure of the ancestral GS gene has been maintained during evolution with some modifications, such as the presence of a plastid targeting sequence in the first exon of GS2 and minor changes in some other exons of GS1 genes.

A detailed analysis of GS transcript abundance in different tissues and organs of poplar allowed us to identify specific expression patterns of the individual members of the gene family (Figures 5 and 7). PtGS2 transcripts were most abundant in leaves as previously reported for other angiosperms where the GS2 isoform is responsible for assimilation of photorespiratory ammonium $[9,10]$. In fact, the promoters of the poplar GS2 duplicates contained cis regulatory elements described in other GS2 genes in angiosperms [18]. An additional role of GS2 is the assimilation of nitrate-derived ammonium in leaves. It is well known that plants differ in the localization of nitrate reduction and assimilation. Thus, some species localize nitrate reduction and assimilation in the roots, whereas other species assimilate nitrate preferentially in the leaves. In poplar, most nitrate assimilation takes place in the leaves [25]. Therefore, high levels of the GS2 isoform are necessary to assimilate the ammonium generated by nitrate reduction within the chloroplast.

Only one of the three PtGS1 duplicates in poplar, PtGS1.1, was also preferentially expressed in leaves and interestingly its expression pattern spatially complemented the observed expression pattern of PtGS2. Thus, PtGS1.1 transcripts were particularly abundant in the older leaves located at the basal part of the tree. These results suggest a relevant role of PtGS1.1 in glutamine biosynthesis associated to photosynthetic metabolism in leaves. Furthermore, the presence of light-regulation boxes [26,27] in the promoter regions of PtGS1.1 duplicates (Figure 4) is consistent with our data and may explain the above described expression pattern in green leaves.

Poplar GS1.2 was preferentially expressed in roots of young trees suggesting a role for this gene duplicate in primary assimilation of nitrogen from soil, as it has been previously described for other cytosolic GS enzymes in plants [28-30]. Interestingly, the relative abundance of PtGS1.2 transcripts increased significantly (12 fold) in poplar leaves infected with Pseudomonas syringae, whereas the expression of other members of the GS gene family was not affected (data not shown). The induction of a GS1 gene in response to pathogen attack has been previously described [31,32]. Moreover, it has been demonstrated in infected tomato leaves and senescing tobacco leaves that the cytosolic isoform involved in nitrogen remobilisation is the product of a GS1 gene preferentially expressed in roots [33,34]. These data, together with our work described here suggest that PtGS1.2 may have a role in nitrogen remobilization during leaf senescence.

In young trees, the maximum expression levels of the twin PtGS1.3 genes were detected in stems and petioles. Furthermore, this member of the poplar GS family exhibited the highest levels of gene expression suggesting it plays an essential role in nitrogen metabolism. The regulatory regions of the PtGS1.3 duplicates contained AC elements involved in the interaction with members of the R2R3 Myb factors regulating the transcription of genes for lignin biosynthesis [35,36]. Similar cis-regulatory elements and trans-acting factors have been found to coordinate lignin biosynthesis and nitrogen recycling in pine [37], suggesting that PtGS1.3 is involved in nitrogen recycling associated to lignification in poplar. Transcriptomic analyses have also suggested a role of Dof family members in the regulation of genes under conditions resulting in increased lignin deposition [38]. The differential regulation of cytosolic GS genes in conifers by a member of the Dof family (Dof5) was recently reported [39] and putative regulatory elements for Dof regulation have been identified in poplar GS genes (Figure 4). Furthermore, we have found that orthologous Dof factors are also involved in the regulation of GS isoforms in poplar (García-Gutiérrez, Avila C, Cánovas FM, unpublished data). The analysis of GS polypeptides in different poplar organs by 2D-PAGE (Figure 6) largely confirmed the expression patterns determined for the duplicated GS genes. The GS polypeptides were resolved in four major spots with differential accumulation in poplar organs. Thus, in the leaves, the GS2 and GS1 polypeptides displayed pI values in the range of the calculated $\mathrm{pI}$ values for the PtGS2 and PtGS1.1 gene expression products (Table 1). In stems, the predominant GS1 polypeptide is predicted to be the expression product of the PtGS1.3 duplicate whereas the major GS1 polypeptide in roots is predicted to be the expression product of PtGS1.2. This conclusion is supported by the close similarity between the $\mathrm{pI}$ values of the GS1 isoforms separated in Figure 6 and the corresponding values deduced from the polypeptides encoded by the PtGS1.3 and PtGS1.2 duplicates (Table 1).

The analysis of transcripts in adult trees during one year of growth (Figure 7) showed that the expression of the poplar GS family members is seasonally regulated. The expression of the PtGS2 duplicate was high in leaves in spring when photosynthesis and photorespiration are at maximum levels [40]. Furthermore, glutamine is required to initiate vegetative protein accumulation during new shoot development in spring [41]. Developing leaves represent a strong sink for nitrogen during active growth [42]. High levels of PtGS1.1 gene expression were also found in leaves of adult trees 
in summer and autumn when the expression of PtGS2 is very low. These data suggest that the GS1.1 isoform could play an important role in the redistribution of nitrogen from poplar leaves to stems during summer and autumn. In leaves, stem, buds and bark of adult trees, extremely low levels of PtGS1.2 transcripts were detected in winter and summer, however, slight increases were observed in spring and autumn. Nitrogen mobilisation in poplar is seasonally regulated with recycling and transport of nitrogen compounds from senescing tissues to storage tissues in autumn and remobilisation of nitrogen reserves to support active growth in spring [42]. In adult trees, PtGS1.3 gene expression was seasonally regulated with particularly high transcript levels in spring and autumn. Transcript abundance was much high in heterotrophic tissues such as stem, buds and bark, with the exception of senescent leaves in autumn.

The role of cytosolic GS in poplar growth and biomasss production has been reported previously $[13,14]$. Furthermore, enhanced GS expression in poplar results in enhanced efficiency of nitrogen assimilation [16]. The role of GS1 in ammonium assimilation and nitrogen remobilisation is particularly important in perennial plants that are able to cope with recurrent periods of growth and dormancy. For example, trees divert large amounts of carbon to the biosynthesis of phenylpropanoids needed to generate lignin, an important constituent of wood. Although lignin does not contain nitrogen, during wood formation there is significant release of nitrogen in the form of ammonium when phenylalanine is deaminated and channeled into lignin biosynthesis and when glycine is decarboxylated in $\mathrm{C} 1$ metabolism. These two metabolic pathways are active in lignifying cells [43]. Ammonium ions released must be reintegrated into metabolism in order to maintain high rates of lignification without affecting nitrogen economy $[12,44]$. In fact, poplar GS1 transcripts and polypeptides accumulate in developing xylem cells where activities of enzymes involved in the phenylpropanoid pathway and $\mathrm{C} 1$ metabolism are high and, therefore, ammonium is liberated $[45,46]$. According to these findings we decided to examine in silico the expression of GS genes during wood formation in hybrid poplar (Populus tremula $\mathrm{x}$ Populus tremuloides) using the microarray data available in Populus DB [47]. Principal component analysis (Additional file 1) showed a high degree of co-expression for PtGS1.3 and relevant genes involved in lignin biosynthesis and $\mathrm{C} 1$ metabolism. In contrast, other members of the GS family also expressed during poplar wood formation (PtGS1.1 and PtGS2) did not show such correlation. Taken together, these data suggest an essential role of PtGS1.3 in lignifying tissues of poplar.

\section{Conclusion}

In the present study the structural and expression analysis of the GS gene family in poplar is presented. The GS gene family consists of 8 different genes exhibiting all structural and regulatory elements consistent with their roles as functional genes. Our results indicate that the family members are organized in 4 groups of duplicated genes, 3 of which code for cytosolic GS isoforms (GS1) and 1 codes for the chloroplast located GS isoform (GS2). Detailed expression analyses have revealed specific spatial and seasonal patterns of GS gene regulation in poplar (Figure 8). These data provide insights into the metabolic function of GS isoforms in poplar and pave the way for future functional studies.

Our analysis shows that Populus trichocarpa is the first plant species in which it was observed the complete $G S$ family duplicated. Considering all data in the present paper, it appears that GS genes have been highly conserved following whole-genome duplication in poplar. In contrast, duplicated members of other gene families in poplar have rapidly diverged $[48,49]$. Some authors argue that genes involved in transcriptional regulation and developmental genes are preferentially retained [50]. It has also been proposed that one of the factors influencing the probability of duplicate gene retention is its connectivity [22]. Our data suggest that GS duplicates could have been retained in order to increase the amount of enzyme in a particular cell type. This possibility could contribute to the homeostasis of nitrogen metabolism in functions associated to changes in glutamine-derived metabolic products. It has been reported that recently duplicated genes play an important role in the functional compensation of metabolic products in Arabidopsis [51]. The presence of duplicated GS genes in poplar could also contribute to diversification of the enzymatic properties for a particular GS isoform through the assembly of GS polypeptides into homo oligomeric and/or hetero oligomeric holoenzymes in specific cell types. Further research is needed to confirm these hypotheses.

\section{Methods}

\section{Plant material}

Experiments were performed with hybrid poplar (Populus tremula x Populus alba, clone INRA 717 1-B4, Institut National de la Recherche Agronomique, INRA). For the expression analysis in different plant organs, plants were micropropagated in vitro on half-strength Murashige and Skoog medium (MS) as described previously [13]. Unless otherwise noted, plantlets were maintained under conditions described previously $[13,14]$. Rooted shoots were transferred to plant growth chambers in plastic pots containing a potting mix (HM3-Agromálaga, 


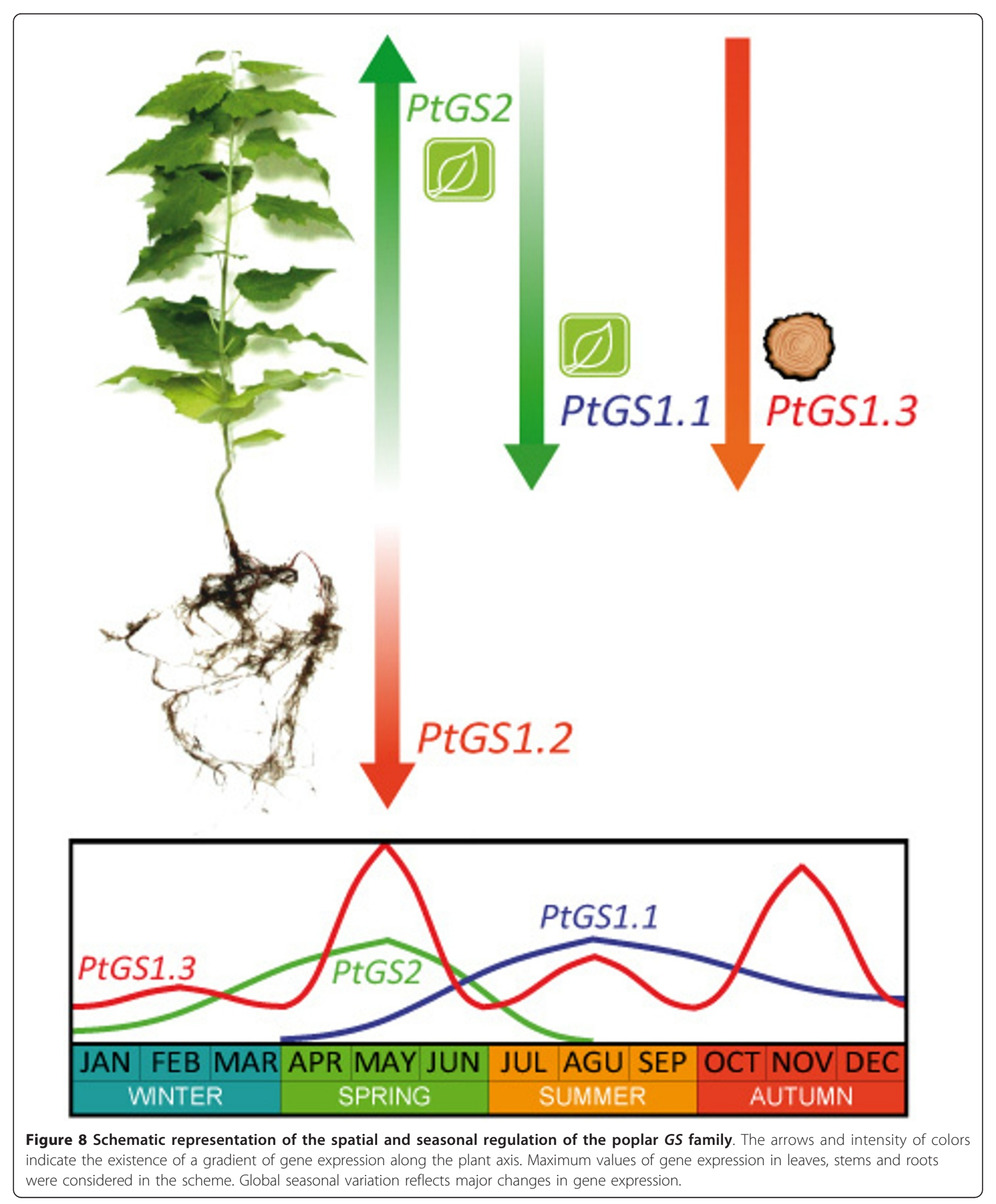


Málaga, Spain) and vermiculite in proportions 1:1. After ex-vitro acclimatization, the plantlets were maintained for 8 weeks in the following conditions: temperature was kept constant at $22^{\circ} \mathrm{C}$, day-length was set at 16 hours, light was supplied at an intensity of $125 \mu \mathrm{mol} \mathrm{m}{ }^{2}$ $\mathrm{s}^{-1}$ and humidity was fixed about $80 \%$. Plants were regularly supplied with a nutrient solution containing 10 $\mathrm{mM}$ potassium nitrate. At the end of the growing period, $P$. tremula $\times$ P. alba plants were harvested and samples taken from 15 different sections from the shoot apex to the root tip.

The aerial regions of the plants was divided into four parts: the apical bud (A), the 1st, 2nd, 3rd, 4th and 5th apical leaves (A1); the intermediate region with the 6th, 7th, 8th, 9th and 10th leaves (A2), and the more basal region including 11th, 12th, 13th, 14th and 15th leaves (A3). Each section was further divided in: L, leaf lamina; $\mathrm{V}$, principal midrib; P, petiole; S, stem. The root was sectioned in R1, principal root and R2, secondary root.

Seasonal analysis of gene expression was monitored in 10-year-old trees of hybrid poplars located in the experimental centre Grice-Hutchinson, Barrio de San Julián, 29004, Málaga, Spain. The samples used were leaves, stems, buds and bark from hybrid trees. The samples were harvested in mid- March, June, September and December of 2008.

\section{Identification of GS gene duplicates and chromosomal mapping}

The GS nucleotide and protein sequences were identified using the Eukaryotic Orthologous Groups section of the Join Genome institute (http://genome.jgi-psf.org/ Poptr1_1/Poptr1_1.home.html). The protein identifiers used in this genome portal have been conserved in our study (Table 1). GS sequences captured from the poplar database were annotated by blastp searches in the GenBank (http://blast.ncbi.nlm.nih.gov/Blast.cgi). The p-distances among the exonic and intronic regions of the GS family were calculated with the phylogenetic program MEGA 4 [52], sewing the intron sections of each gene in continuous sequence. The degree of identity between the genomic regions in which the GS duplicated genes were located was explored by using a strategy of searching microsynteny among the different Linkage Groups. Upstream and downstream genomic sequences were aligned with CLUSTALW [53] and the ORF sequences flanking the GS genes were located manually. Results were then compared with those reported by [17].

\section{Sequence and phylogenetic analysis}

The alignment of the Populus trichocarpa GS protein sequences was carried out with CLUSTALW [53]. The protein sequences used in the construction of the phylogenetic tree were collected from species whose genomes have been fully sequenced. Additionally, sequences of other interesting arboreal species, including Pinus or Picea, have been included. The protein sequences, and their corresponding identifiers, were found in the following databases:

Populus trichocarpa and Sorghum bicolor: http://genome.jgi-psf.org/

Pinus sylvestris and Picea sitchensis: http://www.ncbi. nlm.nih.gov/Genbank/index.html.

Arabidopsis thaliana: http://www.arabidopsis.org/

Oryza sativa: http://rice.plantbiology.msu.edu/

Vitis vinifera: http://www.phytozome.net/

The phylogenetic tree was constructed using the phylogeny platform http://www.phylogeny.fr/[54] and comprised the following steps. Sequences were aligned using T-Coffee (v6.85) using the 10 best local alignments (Lalign_pair), an accurate global alignment (slow_pair). After alignment, ambiguous regions were removed with Gblocks (v0.91b). Minimum length of a block after gap cleaning was set at 10; no gap positions were allowed in the final alignment. All segments with contiguous nonconserved positions greater than 8 were rejected. The minimum number of sequences for a flank position was set at $85 \%$. The phylogenetic tree was reconstructed using the neighbor joining method implemented in the BioNJ program, using as substitution model a Dayhoof PAM matrix and including 1000 bootstraps. Distances were calculated using ProtDist. The DAY substitution model was selected for the analysis [55].

\section{Promoter analysis}

The presence of regulatory elements in the 5'-upstream region of poplar GS genes was analyzed starting in the ATG codon of initiation of translation. Sequences for each pair of duplicated genes were aligned by means of MultAlin [56] in order to locate common regions, and those showing high identity were analyzed to identify putative cis regulatory elements in the plant databases PLACE [57] and PlantCARE [58]. Sequence stretches of 600 base pairs for the GS1 genes and 1300 base pairs for GS2 genes were compared. More distant regions were not considered, because the p-distance values in these regions showed that similarity between the duplicated sequences diminished considerably.

\section{RNA extraction and CDNA synthesis}

Samples from photosynthetic tissues $(0.25 \mathrm{~g})$ or nonphotosynthetic tissues $(0.5 \mathrm{~g})$ were ground under liquid nitrogen with a mortar and pestle in proportions 1:2 and 1:1, respectively. RNA extraction was performed as described by Canales et al. [59] with minor modifications. The RNA was quantified with a NanoDrop ${ }^{\circledR}$ ND- 
1000 spectrophotometer (NanoDrop Technologies, Inc. Wilmington, USA). The integrity of RNA in the samples was verified by agarose gel electrophoresis.

The cDNA synthesis was performed by means of the PrimeScriptTM RT reagent (Perfect Real Time) of Takara BIO Inc. (Otsu, Shiga Japan), following the instructions recommended by the manufacturer. The reaction mix contained $0.5 \mu \mathrm{g}$ of total RNA in a final volume of $10 \mu \mathrm{L}$, which were incubated during $15 \mathrm{~min}$ at $37^{\circ} \mathrm{C}$.

\section{Real-time quantitative PCR (qPCR)}

The 3' untranslated regions of PtGS1.1, PtGS1.2, PtGS1.3 and PtGS2 duplicates were compared to identify sequences with high identity for each pair of duplicated genes. Oligonucleotide primers were designed to amplify specifically the transcripts encoded by each pair of duplicated genes. Sequences of forward and reverse primers follow.

PtGS2-F: GGAGCATCACTTGGATCTAGATGG

PtGS2-R: CAAAACCCAAGAGTAAAAAGGTCC

PtGS1.1-F: ATGGTTGTCTGTCAATTTGTTTGCC

PtGS1.1-R: CCAGCAAGAGTTTTATTTAGATTAG

PtGS1.2-F: GGAATTGAGTATTGGAAGATGATGG

PtGS1.2-R: TATGTTCATAAATGATCAACAGCC

PtGS1.3-F: TGGAAACCATAAGAGATCACCACC

PtGS1.3-R: GAAGAGGCAATTCTTGTACCAAG

PCR products were verified by melting point analysis at the end of each experiment. The identity of the PCR products for each GS duplicate was tested during protocol development by gel electrophoresis and confirmed by DNA sequencing (Additional file 2).

The relative quantification of the gene expression was carried out by qPCR using a thermal cycler (Real System Stratagene MX Swindles PCR 3000PTM, Agilent Technologies, Santa Clara, CA). The qPCR system was the QUANTIMIX EASY SYG (Biotools B\&M Labs S.A. Madrid, Spain) and the protocols followed were those recommended by the manufacturer. The PCR reactions were performed by triplicate using samples without DNA as controls. The volume of the qPCR samples was $2 \mu \mathrm{L}$ containing $10 \mathrm{ng}$ of cDNA from the RT reactions. The amplification program had 3 steps: i) 1 cycle $\left(95^{\circ} \mathrm{C}\right.$, $2 \mathrm{~min})$; ii) 40 cycles, cDNA denaturing $\left(95^{\circ} \mathrm{C}, 15 \mathrm{~s}\right)$, hybridization $\left(55^{\circ} \mathrm{C}, 15 \mathrm{~s}\right)$ and extension $\left(72^{\circ} \mathrm{C}, 30 \mathrm{~s}\right)$; iii) 1 cycle $\left(95^{\circ} \mathrm{C}, 1 \mathrm{~min}\right)$ and 1 cycle $(30 \mathrm{~s})$ for absolute temperatures from $55^{\circ} \mathrm{C}$ to $95^{\circ} \mathrm{C}$ to generate the dissociation curve in order to confirm the specific amplification of each individual reaction.

The relative expression levels were calculated by using actin2 and ubiquitin as reference genes [60]. The initial number of transcripts of the candidate and reference genes $\left(\mathrm{N}_{0}\right)$ was calculated by means of the LinRegPCR software version 11.0 [61]. The normalized $\mathrm{N}_{0}$ was found by calculating the ratio between the averages of the $\mathrm{N}_{0}$ of the replicates and the $\mathrm{N}_{0}$ of the reference genes (normalization factor).

\section{Protein extraction and western blot analysis}

Poplar protein extraction was performed using the following protocol. One gram of plant tissue was homogenized in mortar and pestle with $1 \mathrm{~g}$ of sand and $1 \mathrm{~mL}$ of extraction buffer [0.175 M Tris $\mathrm{pH} 8.8,5 \%$ SDS (w/v), $15 \%$ glycerol (v/v), $0.3 \mathrm{M}$ mercaptoethanol]. The extract was then centrifuged at $10,000 \times \mathrm{g}, 4^{\circ} \mathrm{C}$ for $30 \mathrm{~min}$. The supernatant was mixed with 4 volumes of acetone for 1 $\mathrm{h}$ at $-20^{\circ} \mathrm{C}$ and then centrifuged at $10,000 \times \mathrm{g} 4^{\circ} \mathrm{C}$ for 30 min. The resulting pellet was washed with $80 \%(\mathrm{v} / \mathrm{v})$ acetone and centrifuged two times at $10,000 \times \mathrm{g} 4^{\circ} \mathrm{C}$ for $15 \mathrm{~min}$. The pellet was dried and solubilized in loading buffer for SDS-electrophoresis on $12.5 \%(\mathrm{w} / \mathrm{v})$ polyacrylamide gels. Resolved polypeptides were electrotransferred onto nitrocellulose membranes (Whatman GmbH, Dassel, Germany) and the presence of GS polypeptides was immunorevealed as described by Cánovas et al. [62] using the antiserum raised against recombinant pine GS [19]. Subsequent detection of immunocomplexes was carried out by a peroxidase assay.

\section{Two-dimensional gel electrophoresis}

Two-dimensional gel electrophoresis was carried out as described previously [63]. Poplar proteins were solubilized in isoelectrofocusing (IEF) loading buffer. The amount of protein loaded per gel was $30 \mu \mathrm{g}$. IEF slab gels were $80 \times 70 \times 1 \mathrm{~mm}$ consisting of $5 \%(\mathrm{w} / \mathrm{v})$ polyacrylamide, $8.3 \mathrm{M}$ urea, 2.5\% (v/v) carrier ampholytes (Pharmalyte $\mathrm{pH}$ 4-6). IEF was performed at $200 \mathrm{~V}$ for $2.5 \mathrm{~h}$. The second dimension electrophoresis was also performed in $80 \times 70 \times 1.5 \mathrm{~mm}$ slab gels of $12.5 \%(\mathrm{w} / \mathrm{v})$ polyacrylamide gels containing SDS as described above. The resolved proteins were then transferred to nitrocellulose membranes and immunodetection was performed essentially as described for one-dimensional western blots.

\section{Protein quantification}

Protein levels were determined by the Bradford's procedure [64]. In samples solubilized with SDS protein contents were estimated as described by Ekramoddoullah [65].

\section{Additional material}

Additional file 1: Principal Component Analysis (PCA) of GS genes and genes involved in lignin biosynthesis and C1 metabolism. The expression profiles of GS genes were examined in silico during wood formation in hybrid poplar (Populus tremula $\times$ Populus tremuloides) using 
the microarray data available in Populus DB [48]. Tissue samples were collected from five positions to cover xylem development from cambium meristematic cells: cambium, early expansion, late expansion, secondary wall formation and late cell maturation. GS genes: PtGS1.1-710678, PtGS1.3-827781 and PtGS2-725763; Lignin genes: PtPAL-696959, PtCCOAMT691730, PtAldOMT-345776; C1 metabolism genes: PtGDC-H-570626, PtMTHFR-654300, PtAHCY-540785, PtMTR-738504 and PtMAT-689393. Plot of the analyzed variables (gene expression levels during lignification) on the two first principal components: $90.8 \%$ y $3.3 \%$ of the variance respectively. Most of the gene co-expression values were positively correlated with the first principal component. The second principal component is mainly characterized by the mutually exclusive expression of PtGS1.1-710678 and PtGS2-725763 respectively.

Additional file 2: Predicted and sequenced CDNAs of poplar GS genes. Predicted and sequenced cDNAs of poplar GS genes are listed.

\section{Acknowledgements}

This work was supported by a grant from the Spanish Ministry of Science and Innovation (BIO2009-07490) and by research funds from Junta de Andalucía (group BIO114). We thank Juan Antonio Pérez-Claros for helpul advice on statistical analysis and Remedios Crespillo for excellent technical support. We are very grateful to members of the Kirby and Cánovas laboratories for their kind assistance in various aspects of this work. We also thank Antonio de Vicente for his generous gift of the bacterial strain Pseudomonas syringae pathovar tomato. Angel García-Gutiérrez was granted for Dirección General de Innovación Educativa y Formación del Profesorado of Consejería de Educación y Ciencia (Junta de Andalucía, Spain) to expend one year doing research at the Universidad de Málaga. Edward G. Kirby gratefully acknowledges the Ministerio de Educación y Ciencia of Spain for a sabbatical fellowship in the Cánovas lab.

\section{Author details}

'Departamento de Biología Molecular y Bioquímica, Instituto Andaluz de Biotecnología, Universidad de Málaga, 29071-Málaga, Spain. ²Department of Biological Sciences, Rutgers University, Newark, New Jersey 07102, USA.

\section{Authors' contributions}

VCR carried out experiments. AGG contributed bioinformatic analyses and did illustrations. JC contributed the GPCR work. CA contributed protein work. AGG, CA and FMC conceived this study. EGK and FMC wrote the manuscript. All authors read and approved the final manuscript.

Received: 6 May 2011 Accepted: 25 August 2011

Published: 25 August 2011

\section{References}

1. Lea PJ, Ireland RJ: Nitrogen metabolism in higher plants. In Plant Amino Acids, Biochemistry and Biotechnology. Marcel Dekker, New York Edited by: BK Singh 1999, 1-47.

2. Forde $B G$, Cullimore JV: The molecular biology of glutamine synthetase in higher plants. Oxford Surveys in Plant Molecular and Cell Biology 1989, 6:115-128.

3. Lam HM, Coschigano KT, Oliveira IC, Melo-Oliveira R, Coruzzi GM: The molecular genetics of nitrogen assimilation into amino acids in higher plants. Annual Review of Plant Physiology and Plant Molecular Biology 1996 47:569-593.

4. Unno H, Uchida T, Sugawara H, Kurisu G, Sugiyama T, Yamaya T, Sakakibara H, Hase T, Kusunoki M: Atomic structure of plant glutamine synthetase: a key enzyme for plant productivity. Journal of Biological Chemistry 2006, 281:29287-29296.

5. Seabra AR, Carvalho H, Pereira PJB: Crystallization and preliminary crystallographic characterization of glutamine synthetase from Medicago truncatula. Acta Crystallographica Section F Structural Biology and Crystallization Communications 2009, 65:1309-1312.

6. Sáez AC, Munoz-Chapuli R, Plomion C, Frigerio J, Cánovas FM: Two genes encoding distinct cytosolic glutamine synthetases are closely linked in the pine genome. Federation of European Biochemical Societies Letters 2000, 477:237-243.
7. Leegood R, Lea P, Adcock M, Hausler R: The regulation and control of photorespiration. Journal of Experimental Botany 1995, 46:1397-1414.

8. Masclaux-Daubresse C, Daniel-Vedele F, Dechorgnat J, Chardon F, Gaufichon L, Suzuki A: Nitrogen uptake, assimilation and remobilization in plants: challenges for sustainable and productive agriculture. Annals of Botany 2010, 105:1141-1157.

9. Cren $\mathrm{M}$, Hirel B: Glutamine synthetase in higher plants regulation of gene and protein expression from the organ to the cell. Plant and Cell Physiology 1999, 40:1187-1193.

10. Bernard SM, Habash DZ: The importance of cytosolic glutamine synthetase in nitrogen assimilation and recycling. New Phytologist 2009, 182:608-620

11. Suárez MF, Ávila C, Gallardo F, Cantón FR, García-Gutiérrez A, Claros MG, Cánovas FM: Molecular and enzymatic analysis of ammonium assimilation in woody plants. Journal of Experimental Botany 2002, 53:891-904.

12. Cánovas FM, Avila C, Cantón FR, Cañas RA, de la Torre F: Ammonium assimilation and amino acid metabolism in conifers. Journal of Experimental Botany 2007, 58:2307-2318.

13. Gallardo F, Fu J, Cantón FR, García-Gutiérrez A, Cánovas FM, Kirby EG: Expression of a conifer glutamine synthetase gene in transgenic poplar. Planta 1999, 210:19-26.

14. Jing ZP, Gallardo F, Pascual MB, Sampalo R, Romero J, Torres de Navarra A, Cánovas FM: Improved growth in a field trial of transgenic hybrid poplar overexpressing glutamine synthetase. New Phytologist 2004, 164:137-145.

15. El-Khatib R, Hamerlynck EP, Gallardo F, Kirby EG: Transgenic poplar characterized by ectopic expression of a pine cytosolic glutamine synthetase gene exhibits enhanced tolerance to water stress. Tree Physiology 2004, 24:729-736.

16. Man H, Boriel R, El-Khatib R, Kirby EG: Characterization of transgenic poplar with ectopic expression of pine cytosolic glutamine synthetase under conditions of varying nitrogen availability. New Phytologist 2005, 167:31-39.

17. Tuskan GA, Difazio S, Jansson S, Bohlmann J, Grigoriev I, Hellsten U, Putnam N, Ralph S, Rombauts S, Salamov A, Schein J, Sterck L, Aerts A, Bhalerao RR, Bhalerao RP, Blaudez D, Boerjan W, Brun A, Brunner A, Busov V, Campbell M, Carlson J, Chalot M, Chapman J, Chen GL, Cooper D, Coutinho PM, Couturier J, Covert S, Cronk, et al: The genome of black cottonwood, Populus trichocarpa (Torr. \& Gray). Science 2006, 313:1596-1604.

18. Tjaden G, Edwards JW, Coruzzi GM: Cis elements and trans-acting factors affecting regulation of a non-photosynthetic light-regulated gene for chloroplast glutamine synthetase. Plant Physiology 1995, 108:1109-1117.

19. Cantón FR, García-Gutiérrez A, Crespillo R, Cánovas FM: High-level expression of Pinus sylvestris glutamine synthetase in Escherichia coli. Production of polyclonal antibodies against the recombinant protein and expression studies in pine seedlings. Federation of European Biochemical Societies Letters 1996, 100:205-210.

20. Walker EL, Weeden NF, Taylor CB, Green P, Coruzzi GM: Molecular evolution of duplicate copies of genes encoding cytosolic glutamine synthetase in Pisum sativum. Plant Molecular Biology 1995, 6:1111-1125.

21. Seabra AR, Vieira CP, Cullimore, Carvalho HG: Medicago truncatula contains a second gene encoding a plastid located glutamine synthetase exclusively expressed in developing seeds. BMC Plant Biology 2010, 10:183.

22. Flagel $L E$, Wendel JF: Gene duplication and evolutionary novelty in plants. New Phytologist 2009, 183:557-564.

23. Kumada Y, Benson DR, Hillemann D, Hosted TJ, Rochefort DA, Thompson CJ, Wohlleben W, Tateno Y: Evolution of the glutamine synthetase gene, one of the oldest existing and functioning genes. Proceedings of the National Academy of Sciences USA 1993, 90:3009-3013.

24. Ghoshroy S, Binder M, Tartar A, Robertson DL: Molecular evolution of glutamine synthetase II: Phylogenetic evidence of a non-endosymbiotic gene transfer event early in plant evolution. BMC Evolutionary Biology 2010, 10:198.

25. Black BL, Fuchigami LH, Coleman GD: Partitioning of nitrate assimilation among leaves, stems and roots of poplar. Tree Physiology 2002, 22:717-724.

26. Gidoni $D$, Brosio P, Bond-Nutter D, Bedbrook J, Dunsmuir P: Novel cisacting elements in petunia $\mathrm{Cab}$ gene promoters. Molecular General Genetics 1989, 215:337-344. 
27. Gilmartin PM, Sarokin L, Memelink J, Chua NH: Molecular light switches for plant genes. The Plant Cell 1990, 2:369-378.

28. Sukanya R, Li MG, Snustad DP: Root-specific and shoot-specific responses of individual glutamine synthetase genes of maize to nitrate and ammonium. Plant Molecular Biology 1994, 26:1935-1946.

29. Ishiyama K, Inoue E, Watanabe-Takahashi A, Obara M, Yamaya T, Takahashi H: Kinetic properties and ammonium-dependent regulation of cytosolic isoenzymes of glutamine synthetase in Arabidopsis. Journal of Biological Chemistry 2004, 279:16598-16605.

30. Ishiyama K, Inoue E, Tabuchi M, Yamaya T, Takahashi H: Biochemical background and compartmentalized functions of cytosolic glutamine synthetase for active ammonium assimilation in rice roots. Plant and Cell Physiology 2004, 45:1640-1647.

31. Pérez-García A, Pereira S, Pisarra J, García-Gutiérrez A, Cazorla F, Salema R, de Vicente A, Cánovas FM: Cytosolic localization in tomato mesophyll cells of a novel glutamine synthetase induced in response to bacterial infection or phosphinothricin treatment. Planta 1998, 206:426-434.

32. Tavernier V, Cadiou S, Pageau K, Lauge R, Reisdorf-Cren M, Langin T, Masclaux-Daubresse $C$ : The plant nitrogen mobilization promoted by Colletotrichum lindemuthianum in Phaseolus leaves depends on fungus pathogenicity. Journal of Experimental Botany 2007, 58:3351-3360.

33. Brugière N, Dubois F, Masclaux C, Sangwan RS, Hirel B: Immunolocalization of glutamine synthetase in senescing tobacco (Nicotiana tabacum L.) leaves suggests that ammonia assimilation is progressively shifted to the mesophyll cytosol. Planta 2000, 211:519-527.

34. Olea F, Perez-García A, Cantón FR, Rivera ME, Cañas R, Avila C, Cazorla FM, Cánovas FM, de Vicente A: Up-regulation and localization of asparagine synthetase in tomato leaves infected by the bacterial pathogen Pseudomonas syringae. Plant and Cell Physiology 2004, 45:770-780.

35. Patzlaff A, McInnis S, Courtenay A, Surman C, Newman LJ, Smith C, Bevan MW, Mansfield S, Whetten RW, Sederoff RR, Campbell MM: Characterisation of a pine MYB that regulates lignification. The Plant Journal 2003, 36:743-54.

36. Goicoechea M, Lacombe E, Legay S, Mihaljevic S, Rech P, Jauneau A, Lapierre C, Pollet B, Verhaegen D, Chaubet-Gigot N, Grima-Pettenati J: EgMYB2, a new transcriptional activator from Eucalyptus xylem, regulates secondary cell wall formation and lignin biosynthesis. The Plant Journal 2005, 43:553-567.

37. Gómez-Maldonado J, Avila C, de la Torre F, Cañas R, Cánovas FM, Campbell MM: Functional interactions between a glutamine synthetase promoter and MYB proteins. The Plant Journal 2004, 39:513-526.

38. Rogers LA, Dubos C, Surman C, Willment J, Cullis IF, Mansfield SD, Campbell MM: Comparison of lignin deposition in three ectopic lignification mutants. New Phytologist 2005, 168:123-140.

39. Rueda-López M, Crespillo R, Cánovas FM, Avila C: Differential regulation of two glutamine synthetase genes by a single Dof transcription factor. The Plant Journal 2008, 56:73-85.

40. Millard P, Grelet GA: Nitrogen storage and remobilization by trees: ecophysiological relevance in a changing world. Tree Physiology 2010, 30:1083-1095

41. Tian W-M, Peng S-Q, Hao B-Z, Wu J-L, Hu Z-H, Cui K-M: Poplar trees (Populus canadensis Moench) initiate vegetative storage protein accumulation during new shoot development in spring. Journal of Integrative Plant Biology 2005, 47:717-725.

42. Cooke JEK, Weih M: Nitrogen storage and seasonal nitrogen cycling in Populus: bridging molecular physiology and ecophysiology. New Phytologist 2005, 167:19-30.

43. Cantón FR, Suárez MF, Cánovas FM: Molecular aspects of nitrogen mobilization and recycling in trees. Photosynthesis Research 2005, 83:265-278.

44. van Heerden PS, Towers GH, Lewis NG: Nitrogen metabolism in lignifying Pinus taeda cell cultures. Journal of Biological Chemistry 1996, 271:12350-12355.

45. Avila C, Suárez MF, Gómez-Maldonado J, Cánovas FM: Spatial and temporal expression of two cytosolic glutamine synthetase genes in Scots pine: functional implications on nitrogen metabolism during early stages of conifer development. The Plant Journal 2001, 25:93-102.

46. Sakurai N, Katayama Y, Yamaya T: Overlapping expression of cytosolic glutamine synthetase and phenylalanine ammonia-lyase in immature leaf blades of rice. Physiologia Plantarum 2001, 113:400-408.
47. Hertzberg M, Aspeborg H, Schrader J, Andersson A, Erlandsson R, Blomqvist K, Bhalerao R, Uhlen M, Teeri TT, Lundeberg J, Sundberg B, Nilsson P, Sandberg G: A transcriptional roadmap to wood formation. Proceedings of the National Academy of Sciences USA 2001, 98:14732-14737.

48. Kalluri UC, DiFazio SP, Brunner AM, Tuskan GA: Genome-wide analysis of Aux/IAA and ARF gene families in Populus trichocarpa. BMC Plant Biology 2007, 7:59.

49. Lan T, Yang ZL, Yang X, Liu YJ, Wang XR, Zeng QY: Extensive functional diversification of the Populus glutathione $\mathrm{S}$-transferase supergene family. The Plant Cell 2009, 21:3749-3766.

50. De Bodt S, Maere S, Van de Peer Y: Genome duplication and the origin of angiosperms. Trends in Ecology and Evolution 2005, 20:591-597.

51. Hanada K, Sawada Y, Kuromori T, Klausnitzer R, Saito K, Toyoda T, Shinozaki K, Li WH, Hirai MY: Functional compensation of primary and secondary metabolites by duplicate genes in Arabidopsis thaliana. Molecular Biology Evolution 2011, 28:377-382.

52. Tamura K, Dudley J, Nei M, Kumar S: MEGA4: Molecular Evolutionary Genetics Analysis (MEGA) software version 4.0. Molecular Biology and Evolution 2007, 24:1596-1599.

53. Larkin MA, Blackshields G, Brown NP, Chenna R, McGettigan PA, McWilliam H, Valentin F, Wallace IM, Wilm A, Lopez R, Thompson JD, Gibson TJ, Higgins DG: Clustal W and Clustal X version 2.0. Bioinformatics 2007, 23:2947-2948.

54. Dereeper A, Guignon V, Blanc G, Audic S, Buffet S, Chevenet F, Dufayard JF, Guindon S, Lefort V, Lescot M, Claverie JM, Gascuel O: Phylogeny.fr: robust phylogenetic analysis for the non-specialist. Nucleic Acids Research 2008, 36:W465-469.

55. Notredame C, Higgins DG, Heringa J: T-Coffee: A novel method for fast and accurate multiple sequence alignment. Journal Molecular Biology 2000, 8:205-217, 302

56. Corpet $\mathrm{F}$ : Multiple sequence alignment with hierarchical clustering. Nucleic Acids Research 1988, 16:10881-10890.

57. Higo K, Ugawa Y, Iwamoto M, Korenaga T: Plant cis-acting regulatory DNA elements (PLACE) database. Nucleic Acids Research 1999, 27:297-300.

58. Lescot M, Dehais P, Thijs G, Marchal K, Moreau Y, Van De Peer $Y$, Rouze $P$, Rombauts S: PlantCARE, a database of plant cis-acting regulatory elements and a portal to tools for in silico analysis of promoter sequences. Nucleic Acids Research 2002, 30:325-327.

59. Canales J, Flores-Monterrosso A, Rueda-López M, Avila C, Cánovas FM: Identification of genes regulated by ammonium availability in the roots of maritime pine trees. Amino Acids 2010, 39:991-1001.

60. Brunner AM, Yakovlev IA, Strauss SH: Validating internal controls for quantitative plant gene expression studies. BMC Plant Biology 2004, 4:14.

61. Ruijter JM, Ramakers C, Hoogaars W, Bakker O, Van Den Hoff MJB, Karlen Y, Moorman AFM: Amplification efficiency: linking baseline and bias in the analysis of quantitative PCR data. Nucleic Acids Research 2009, 37:45.

62. Cánovas FM, Cantón FR, Gallardo F, García-Gutiérrez A, de Vicente A: Accumulation of glutamine synthetase during early development of maritime pine (Pinus pinaster) seedlings. Planta 1991, 185:372-378.

63. Ávila C, García-Gutiérrez A, Crespillo R, Cánovas FM: Effects of phosphinothricin treatment on glutamine synthetase isoforms in Scots pine seedlings. Plant Physiology and Biochemistry 1998, 36:857-863.

64. Bradford M: A rapid and sensitive method for the quantitation of microgram quantities of protein utilizing the principle of protein-dye binding. Analytical Biochemistry 1976, 72:248-254.

65. Ekramoddoullah A: A method for the determination of conifer foliage protein extracted using sodium dodecyl sulphate and mercaptoethanol. Phytochemical analysis 1995, 6:20-24.

doi:10.1186/1471-2229-11-119

Cite this article as: Castro-Rodríguez et al:: The glutamine synthetase gene family in Populus. BMC Plant Biology 2011 11:119. 